\title{
Repository of basic digital skills for Moroccan doctoral students "University case of study: Hassan II Casablanca"
}

\author{
Redouane FIKRI ${ }^{1}$, Malika TRIDANE ${ }^{1,2}$, Said BELAAOUAD ${ }^{1}$ \\ ${ }^{1}$ Laboratory of Physical Chemistry of Materials, Faculty of Science Ben M'sik \\ University Hassan II Casablanca \\ ${ }^{2}$ Regional Center for Teaching and Professional Training-Casablanca, Morocco \\ fikri.redouane@gmail.com
}

\begin{abstract}
Being a doctoral student is not easy because it presupposes having a number of technical skills, among which digital skills, defined by the European Commission (2006) as "the safe and critical use of the technologies of the society of the information" and the variety of digital use in the personal and professional context, allows us to ask the question that any doctoral student should master and acquire in terms of digital skills? And on what basis can we define these skills?

In this work we expect to develop a baseline of digital skills, is a document that includes the set of essential digital skills that represents a fundamental tool for the doctoral student who can in no way bypass it. And for this, we conducted interviews with about thirty university professors from different faculties of Hassan II University in Casablanca to arrive to a draft of this reference system, then we proceeded to its validation with a second group of 45 teachers in the same university, while studying the correlations existing between the degree of importance of the fields of numerical competences and the belonging to a faculty of the university in question using the khi2 test.
\end{abstract}

Keywords: Numerical Inequalities, Second Degree Digital Divide, Numerical Skills, Doctoral Students

Received: 2 June 2019, Revised 13 August 2019, Accepted 27 August 2019

DOI: $10.6025 / \mathrm{jdp} / 2019 / 9 / 4 / 112-116$

(C) 2019 DLINE. All Rights Reserved

\section{Introduction}

Nowadays, the use of digital technology in everyday life is intense, given its speed in obtaining and transmitting information. VitaliRosati (2014) insists that "digital technology not only changes practices but also their meaning"1. The educational world is no exception to this rule since digital technology is part of the didactic and pedagogical tools of teaching; it has even transformed the techniques of the scientific practice of researchers.

In this context, the notions of numerical skills and repositories of expertise stir up a lot of interest from researchers in the field of training. Despite an abundance of literature on digital technology, the works addressing these two notions among student

112 Journal of Data Processing Volume 9 Number 4 December 2019


researchers remain very rare.

In general, The notion of competence, a polysemous term that gives rise to many debates in scientific writings, is referred, according to Talbot (cited in Basque, J. 2015) ${ }^{2}$, to knowledge put into action in an effective way in the face of a group of situations situated in a context, while the term digital competence or e-skills is defined by the European Commission (2006) as "the safe and critical use of information society technologies"3 more importantly, it covers the knowledge and skills necessary for a person to be able to use computer and modern communication tools to achieve objectives in their personal or professional life (Economic and Social Council, 2018) ${ }^{4}$. As for the reference system, it is presented as an inventory of skills needed for activities and the finalized inventory of these activities themselves (Cuq, 2003: 212) ${ }^{5}$. This is the case, the repository of expertise is an overall description of the skills expected of a student at the end of a training or part of training ${ }^{6}$.

At the light of the above definitions, we can suggest a definition in our repository of digital expertise as a document that includes the set of essential digital skills that represents a fundamental tool for the doctoral student who cannot bypass it, in any way.

\begin{tabular}{|c|c|}
\hline Domain of competence & Digital Skills \\
\hline \multirow{3}{*}{$\begin{array}{l}\text { Mastery of the digital } \\
\text { work environment and } \\
\text { job security }\end{array}$} & $\begin{array}{l}\text { Recognize the digital language and identify the different basic hardware and software elements } \\
\text { (Office, Windows ...). }\end{array}$ \\
\hline & Organize, manipulate, personalize and manage your workstation in an autonomous way. \\
\hline & Ensure data protection by securing your workstation against threats and viruses. \\
\hline \multirow{6}{*}{$\begin{array}{l}\text { Analysis and } \\
\text { processing of digital } \\
\text { information }\end{array}$} & Develop an information search strategy. \\
\hline & Conduct oriented searches to find articles related to a specific search. \\
\hline & $\begin{array}{l}\text { Know how to target by Web search the sites to make communications or publications in line } \\
\text { with expectations. }\end{array}$ \\
\hline & $\begin{array}{l}\text { Analyze, criticize and evaluate the reliability, relevance and credibility of the information } \\
\text { found. }\end{array}$ \\
\hline & Follow and monitor technological developments in the search for information. \\
\hline & Evaluate the authenticity of the documentation and the reliability of the sites consulted. \\
\hline \multirow{4}{*}{$\begin{array}{l}\text { Communication and } \\
\text { exchange of digital } \\
\text { information }\end{array}$} & Communicate and exchange documents through digital tools. \\
\hline & Contribute and collaborate remotely. \\
\hline & Respect the standards of communication and exchange online. \\
\hline & Know how to exploit the possibilities of exchange and storage of documents via the Internet. \\
\hline \multirow{3}{*}{$\begin{array}{l}\text { Web Design } \\
\text { and Production }\end{array}$} & Produce and produce a well organized and organized digital document. \\
\hline & Publish and broadcast on the Web. \\
\hline & Apply licenses and reproduction rights. \\
\hline
\end{tabular}

Table 1. Of basic digitals skills 
Digital competence is a moving and multifaceted goal, constantly evolving as new technologies emerge, therefore this repository forms an evolving, unfixed system, and does not claim to provide a description or complete model of all the skills that should be acquired by the doctoral student, but however it defines a common sphere of general digital skills that student researchers in all branches are expected to possess.

For that, one wonders, what should any doctoral student master and then acquire in terms of digital skills? And on what basis can we define these skills?

In this contribution, we aim to identify the unavoidable digital skills for Moroccan doctoral students of any specialty confused on one hand, and develop a baseline of digital skills that will be used to monitor the evolution of e-skills during their doctoral studies; all while formulating a self-assessment grid for future doctoral students.

\section{Methodology}

We have undertaken a methodology called van der Maren's research-development ${ }^{8}$, the main objective of which is the development of a baseline of digital skills for doctoral students of different specialties.

Our approach consists of identifying the numerical skills necessary for any doctoral student of today through interviews with about thirty professors (researchers and thesis directors), of the Casablanca Hassan II University, including 10 teachers from the Faculty of Arts and Sciences, 10 of the Faculty of Arts and Humanities and 10 professors of the Faculty of Legal and Social Economical Sciences), then develop a draft of the reference document which will be validated by another group of 45 professors teaching at the same university, each faculty representing $1 / 3$ of professors or 15 professors.

We used the chi-squared statistical independence test and cross-analyzed to look for existing correlations between faculty affiliation and digital skill domains, using a likert scale of 1 to 5 to measure the level of importance of the digital skills domain, with 1 being "not at all important" and 5 being "very important".

\section{Results and Discussions}

In this part, we present the repository after its elaboration, classifying the sixteen identified competences into four areas of competence.

On a scale of 1 to 5,95.55\% of professors (or 43 professors) considered that this reference is very important because it encompasses all the digital skills required for any doctoral student today, against $4.44 \%$ being 2 teachers considering it just important.

We review the four areas of competence from interviews with the first group of faculty and the existing correlation between faculty affiliation and degree of jurisdictional importance with the second group:

- For the first area of expertise, namely, mastery of the digital work environment and job security; the professors interviewed almost unanimously (27/30) or $90 \%$ agreed on the need for all doctoral students to be autonomous with computer tools (software and hardware) especially for carrying out the daily tasks related to research scientifically, to be able to protect itself and to solve problems of malicious attacks that threaten the integrity of computer security, because the security of the workstation and its data is one of the most important professional practices of the doctoral student today.

Regarding the degree of importance (41/45) teachers or $91 \%$ qualify it as very important, however $9 \%$ or $(4 / 45)$ teachers qualify it as simply important, No dependence between this area of expertise and a specific faculty is recorded $(\chi 2=\mathbf{3}, d l l=\mathbf{8}, \boldsymbol{p}=$ 0.9343).

- For the second area of expertise; that of analysis and processing of digital information, the majority of professors $93.33 \%$ or $(28 / 30)$ have raised the skills related to this field, because it is essential for doctoral students on the one hand for a research on the Web is successful in the face of the large flow of existing information, to establish a search strategy in the form of a route that will make it possible to return to the objective, that is to say to the information sought and of course evaluate and analyze this information using the evaluation criteria so that it is reliable, relevant and consistent.

114 Journal of Data Processing Volume 9 Number 4 December 2019


As for the degree of importance $86.66 \%$ professors or(39/45) judged that the skills of this field are very important for doctoral students against $13.33 \%$ teachers or(6/45) placing them in the largest category, based on the results of the chi-squared test we can no longer reject the hypothesis of independence between the faculty of study and these fields of competence $(\chi \mathbf{2}=\mathbf{3}, \mathbf{d l l}$ $=\mathbf{8}, p=\mathbf{0 . 9 3 4 3 )}$.

For the third domain; the communication and the exchange of digital information, (27/30 of teachers or $90 \%$ mentioned this component of skills since all doctoral students must be equipped with an ability to communicate using all the digital tools that are available to them; and move much more towards digital groups working to achieve a high level of quality by benefiting from the synergies of a collective, and develop their skills by appropriating different tools, channels of dissemination, sharing and creation of information to ensure effective communication with certain degrees of professionalism.

Regarding the degree of importance and correlation, $91 \%$ or (41/45teachers) qualify very important, while for $9 \%$ or(4/45teachers) is important. The chi-squared test two did not record any dependence between faculty membership and this skill register $\left(\chi^{2}=\right.$ $2, d l l=8, p=0.9810$ ).

- In the field of Design and Production on the Web; the totality of professors surveyed (30/30)or 100\% have reached this area of expertise, under the pretext that all doctoral students are expected to produce articles, scientific publications in newspapers and contents of different audio formats throughout their doctoral studies. , video ..., on the web for which they are obliged to know and respect the rights of the authors and their intellectual properties, and to produce in an orderly and logical way the norms in effect and finally to appropriate the methods and skills needed to write scientific publications and ensure the avoidance of plagiarism.

This field is perceived by $100 \%$ or (45/45) of the teachers having validated this reference system as very important for any doctoral student whatever his specialty or his faculty.

No dependence between the faculty membership variable and this skill domain is recorded $(\chi 2=\mathbf{0}, \boldsymbol{d l l}=\mathbf{8}, \boldsymbol{p}=\mathbf{1})$.

\section{Conclusion}

This repository does not claim complete scientific completeness, but it is just a starting point that will certainly serve as a standard for cross-curricular training organized by the faculties for the benefit of doctoral students. However, it is absolutely necessary to carry out a descriptive and comparative analysis of numerical skills among doctoral students from the various faculties (sciences, letters and human sciences and from the legal and social economics sciences) belonging to Casablanca Hassan II University to endow each faculty a specific training plan meeting their needs, with the goal of having at the end of the doctoral cycle, almost equal winners in basic digital skills.

\section{References}

[1] Salmi, L. R. (2001). Principes de la communication oralescientifique : comment passer d'une bonne étude à une bonne présentationorale. Revue Médicale de l'AssuranceMaladie. 2001 avril-juin; 32, 83-92.

[2] Bassiri, M., Boulahouajeb, A., Aichi, Y., Belaaouad, S., Radid, M. (2018). Distance learning - A powerful vector of the enhancement of socio-professional competences: Case of the training of contract teachers in Regional Centre of Training and Education, Morocco. Asia Life Sciences. 16 (1) 11-19.

[3] Bassiri, M., Marouane, S., Tridane, M., Belaaouad, S., Radid, M. (2018). Alternating training and organizational learning: From an ambivalent relationship towards the development of a reflexive and metacognitive practice. Asia Life Sciences. 16(1) 205-215.

[4] Pitchai, B., Mohammed, N. I., Gowraganahalli, J. (2013). The basic concepts of scientific research and communication. Journal of Pharmacology \& Pharmacotherapeutics. 4 (2) 130-138.

[5] Paul Glover. (2008). Guide de communication scientifiqueorale, l'Association francophone pour le savoir; 29 aout 2008. p 25.

[6] Zerraf, S., Zain, S., Khyati, A., Tridane, M., Belaaouad, S. (2019). A pedagogical approach to educational communication in the educational context. International Journal of Advanced Education and Research, (January), 4(1) 01-04. 
[7] Papi, C. (2012). Des référentiels à la validation des compétencesnumériques: questionnements et dispositifs, Questions Vives [Online], 7 (17), Online since 15 September 2012, connection on 16 October 2018. URL :http://journals.openedition.org/ questionsvives/986

[8] Dominique, W. (2003). Fracture numériqueou facture numérique ?, In: Jauréguiberry F. et Proulx S., Internet, nouvelespacecitoyen?, Paris, l'Harmattan, p. 31-35 in Houssein; Les personnesâgées et la fracture numérique de, second degré: l'apport de la perspective critique en communication repérésur: https://journals.openedition.org/rfsic/1294?lang=fr

[9] Jean-Pierre Cuq, (2003). Dictionnaire de didactique du français langue étrangère et seconde, Clé International, Paris ISBN : 9782-09-033972-7 